\title{
Viral and Atypical Pathogens Epidemiology of a Large Cohort of Patients with Acute Respiratory Tract Infections in Shaanxi Province, Northwest China
}

\section{Meng Li}

Xi'an Jiaotong University Medical College First Affiliated Hospital

Xinyu Liu

Xi'an Jiaotong University Medical College First Affiliated Hospital

Tian Yang

Xi'an Jiaotong University Medical College First Affiliated Hospital

Ruiqing He

Xi'an Jiaotong University Medical College First Affiliated Hospital

\section{Xuan Guo}

Xi'an Jiaotong University Medical College First Affiliated Hospital

Mingwei Chen ( $\square$ chenmw36@163.com )

\section{Research}

Keywords: Acute respiratory tract infections, Respiratory viruses, Atypical pathogens, Epidemiology, Etiology

Posted Date: August 6th, 2020

DOI: https://doi.org/10.21203/rs.3.rs-51652/v1

License: (c) (1) This work is licensed under a Creative Commons Attribution 4.0 International License. Read Full License 


\section{Abstract}

Purpose To analyze and summarize the etiological and epidemiological characteristics of acute respiratory tract infections (ARIs) in northwest China for improving the clinical management and prevention of local ARIs.

Methods Patients with ARIs in the Shaanxi Province from January 2014 to December 2018 were retrospectively analyzed, indirect immunofluorescence assay (IFA) was used to detect IgM antibody of eight respiratory pathogens.

Results A total of 15543 eligible patients was included in this study. Overall, 36.01\% patients (5597/15543) were positive for at least one of eight pathogens, among which single and mixed infections was accounted for 74.65\% (4178/5597) and 25.35\% (1419/5597), respectively. Mycoplasma (MP) showed the highest detection rate (18.12\%), followed by influenza virus B (Flu B, 11.65\%), chlamydia (CP, 7.00\%), respiratory syncytial virus(RSV, 4.18\%), parainfluenza virus (PIV, 2.83\%), influenza virus $A($ Flu $A, 1.69 \%)$, legionella (LP, $1.00 \%$ ) and adenovirus (ADV, 0.70\%). Flu B (17.54 \%, 759/4327) was the most prevalent virus in patients aged less than 18 years. In addition, this group were more likely to have mixed infections. Autumn and winter were the high-occurrence season for ARIs.

Conclusion These findings serve as a reference for local health authorities to develop further plans for the prevention and control of ARIs.

\section{Introduction}

Acute respiratory tract infections (ARIs) are a global public health issue due to its high morbidity and mortality, especially in infants and children. ${ }^{1-4}$ Pathogens affect the upper and lower respiratory tracts, leading to diseases such as pharyngitis, laryngitis, bronchitis, bronchitis and pneumonia. ${ }^{3}$ Respiratory syncytial virus (RSV), influenza virus A (Flu A), influenza virus B (Flu B), parainfluenza virus (PIV) and adenovirus (ADV) are considered to be the common pathogens of most ARIs. ${ }^{5} \mathrm{RSV}$ is the leading cause of severe lower respiratory tract infection (LRTIs) in infants and young children, ${ }^{6,7}$ while influenza virus (IFVs) is the main pathogen causing LRTIs in hospitalized adults. ${ }^{8}$ In addition, with the increase of antibiotic resistance rate and the development of pathogen detection technology, the research on mycoplasma (MP), chlamydia (CP), legionella (LP) and other atypical pathogens has been gradually deepened, and their role in respiratory tract infections has aroused people's attention. ${ }^{9-11}$

Differences in spatial, temporal and population distribution are among the characteristics of respiratory viruses and atypical pathogens infections. Although several epidemiological studies on ARIs have been reported in other countries and other area in China, the epidemiological characteristics of common pathogens of ARIs are different due to inclusion criteria, climate, environmental pollution, population and other factors. ${ }^{12-18}$ Moreover, most of these studies only conducted epidemiological analysis on children or single pathogens, and did not include the data of this study. 
As a core city in northwest China, the spread and prevalence of respiratory diseases are more likely to occur in Xi'an due to its rapid industrial development, large floating population, serious environmental pollution, etc. Thus, the epidemiology of viral and atypical pathogens etiologies associated with ARIs in Xi'an, Shaanxi Province, were presented in this study and aims to provide basic data of etiologies of ARIs to direct local disease prevention and control and clinical diagnosis and treatment.

\section{Methods}

\subsection{Subjects and Data collection}

A total of 15543 patients with ARIs admitted to the department of respiratory medicine and pediatrics of the First Affiliated Hospital of Xi 'an Jiaotong University, Shaanxi, China, from January 2014 to December 2018 were enrolled in the study, including upper and lower respiratory tract infections, such as sinusitis, tonsillitis, acute bronchitis, pneumonia, bronchiectasis with infection, acute exacerbation of chronic obstructive pulmonary disease, acute attack of bronchial asthma, lung cancer with infection, and pneumoconiosis with infection, ect.

The diagnosis for each enrolled patients was made by physicians and based on standard clinical criteria. All patients enrolled in this study must meet the following characteristics: (1) at least one of the following conditions: fever $\left(\geq 37.5^{\circ} \mathrm{C}\right.$ ), chills, leukocytosis (white blood cell count $>10 \times 10^{9} / \mathrm{L}$ ) or leukopenia (white blood cell count $\left.<4 \times 10^{9} / \mathrm{L}\right)$; (2) at least one of the following signs/symptoms: rhinorrhea, nasal congestion, pharyngalgia, cough, suptum, shortness of breath, dyspnea, lung auscultation abnormality (rale or wheeze) and chest pain. Baseline, examination data and relevant information were extracted from the Electronic Medical Records. This study was approved by the Ethics Review Committee of the First Affiliated Hospital of Xi 'an Jiaotong University, informed consent was waived for non-traumatic retrospective study.

\subsection{Detection of respiratory pathogens}

PNEUMOSLIDE IgM kit (VIRCELL PNEUMOSLIDE; VIRCELL, GRANADA, Spain) was used to detect IgM antibody from the clinical samples. The detected respiratory viruses included Flu A, Flu B, IFV, PIV (serum types 1, 2 and 3), RSV, MP, CP and LP.

\subsection{Statistical analysis}

SPSS 18.0 statistical software (SPSS Inc, Chicago, IL) and Microsoft Excel (Microsoft Corp., Redmond, WA) were used for data analysis, Mann-Whitney $U$ test or t-test were used to compare measurement data of two groups and comparison of measurement data in more than two groups used Kruskal- Wallis $\mathrm{H}$ test or ANOVA test. The chi-square test were used to compare the positive detection rate of various pathogens in respiratory tract in different groups. $P<0.05$ was considered to be statistically significant.

\section{Results}




\subsection{Baseline Characteristics}

A total of 15543 patients with ARIs were collected in this study, including 9725 males (62.57\% of total) and 5818 females (37.43\% of total), with an average age $49.33 \pm 19.31$ years, the ages of the eligible patients from 21 days to 87 years old. The subjects included 5701 (36.68\%) upper respiratory infection (URTIs) and 9842 (63.32\%) LRTIs, the baseline characteristics are shown in Table 1.

\subsection{Overall detection rate of eight common pathogens}

As shown in Table 2, among the 15543 samples, 5597 specimens carried at least one virus or atypical pathogen, with a positive detection rate of $36.01 \%$, of which $4178(74.65 \%)$ were single infection and 1419 (25.35\%) were mixed infection. The most predominant pathogen was MP, with a detection rate of $18.12 \%$ (2816/15543), followed by Flu B $(11.65 \%, 1811 / 15543)$, CP $(7.00 \%, 1088 / 15543)$, RSV $(4.18 \%$, 649/15543), PIV $(2.83 \%, 440 / 15543)$, Flu A $(1.69 \%, 26 / 15543)$, LP $(1.00 \%, 156 / 15543)$ and ADV $(0.70 \%, 109 / 15543)$.

\subsection{Detection rate of virus and atypical pathogen from different gender groups}

As shown in Table 3 , there was no significant difference in total positive detection rate between different genders $\left(X^{2}=1.15, P=0.284\right)$. However, the detection rate of Flu $A, M P$ and $A D V$ was significantly higher in male (Flu A: $\chi^{2}=6.90, P=0.009 ;$ MP: $\chi^{2}=15.70, P<0.001 ; A D V: \chi^{2}=7.51, P=0.006$ ), the positive detection rate of PIV and mixed infection was higher in female (PIV: $\chi^{2}=22.34, P<0.001$; Mixed infection: $\chi^{2}=26.73$, $P<0.001)$.

\subsection{Detection rate of viral and atypical pathogen from different age groups}

All of the ARIs patients are divided into four age groups, representing ages of $<18,18-45,46-69$ and $>69$. As shown in Table 4, the predominant pathogen among different age groups varied. In age $<18$ years, Flu B $(17.54 \%, 759 / 4327)$ was the most prevalent virus, followed by MP $(10.98 \%, 475 / 4327)$ and RSV (8.20\%, 355/4327). In Age 18-45, MP (33.76\%, 1018/3014) had the highest incidence, followed by CP $(7.53 \%, 227 / 3014)$ and Flu B $(4.28 \%, 129 / 3014)$. In the groups of $46-69$ and $>69$, MP (middleaged:19.27\%,726/3767; elderly:13.46\%,597/4435) was the most predominant pathogens. The positive detection rates of Flu A, Flu B, PIV, RSV and MP were significantly different in different age groups (Flu A: $\chi^{2}=9.07, P=0.028 \otimes$ Flu $\mathrm{B}: \chi^{2}=9.72, P=0.021, \mathrm{PIV}: \chi^{2}=22.83, P<0.001, \mathrm{RSV}: \chi^{2}=86.8, P<0.001, \mathrm{MP}$ :

$\chi^{2}=134.45, P<0.001$ ), and all of them, except MP, were infected frequently in patients under 18 years old, and MP was most common in patients aged 18-45 years. In addition, the mixed infection rate $(11.05 \%)$ of Age $<18$ years was significantly higher than that of other age groups

\subsection{Detection rate of virus and atypical pathogen from different season groups}

According to the meteorological division method, all the patients were divided into four groups: Spring (March, April and May), Summer (June, July and August), Autumn (September, October and November) 
and Winter (January, February and December). The results showed that the common respiratory infection in the northwest China was seasonal, with higher detection rates in Autumn $(39.65 \%, 1287 / 3246)$ followed by Winter $(37.37 \%, 1727 / 4622)$, Summer $(36.21 \%, 1439 / 3974)$ and Spring $(30.91 \%, 1144 / 3701)$, with significant differences in pathogen detection rates in different seasons $\left(\chi^{2}=64.17, P<0.001\right)$. Flu A, Flu $B, A D V$ and MP mainly detected in winter, PIV mostly occurred in spring, CP, LP and RSV were more infected in autumn, mixed infections were common in autumn and spring (Table5, Figure 1). The detection rate of all pathogens in different seasons was statistically significant $(P<0.001)$.

\section{Discussion}

ARIs is the third leading cause of death in the world, causing a major medical care and economic burden. ${ }^{6}$ LRT Is is a significant source of morbidity and mortality, especially in children under 5 years. ${ }^{19}$ Although viral infection is the dominant cause of ARIs, the proportion of infections with atypical pathogens is increasing due to the abuse of antibiotics and the development of detection technology. ${ }^{9-11}$ At present, several studies on the epidemiology and etiology of respiratory pathogens of children in different areas have been reported, ${ }^{7,16,20-23}$ however, studies on ARIs both in hospitalized children and adults are limited, and the epidemiological and etiological data of ARIs in different regions and hospitals have not been systematically summarized. Current report analyze the epidemiological characteristics of eight common pathogens in the northwest China, providing references for local disease prevention and clinical diagnosis and treatment.

The result of this study shows that the top three most prevalent pathogens were MP $(18.12 \%$, $2816 / 5597)$, Flu B $(11.65 \%, 1811 / 5597)$ and CP $(7.00 \%, 1088 / 5597)$. The total positive detection rate is $36.01 \%$ (5597/15443) in Xi'an, which was similar with the previous study in Turkey (33.4区) and Shandong province in China (35.75区), ${ }^{12,18}$ and significantly higher than that reported in Beijing (5.64\%), Shenzhen (14.55\%), Suzhou (13.6\%) and Gansu province in China (29.2\%), ${ }^{13-16}$ but lower than that reported in north China (39.3\%). ${ }^{17}$ The finding also illustrates that the mixed infections rate is $9.13 \%(1419 / 15543)$ in northwest China, which is significant lower than that in Shandong province (15.67\%), ${ }^{18}$ but higher than that in Beijing (2.13\%), Gansu province (4.70\%) and north China (7.6\%). ${ }^{13}, 14,17$

Similar to the studies in Turkey, other area in China including Suzhou, Shandong and Gansu province, ${ }^{12,}$ $14,15,18$ Flu B is the most common respiratory virus in Xi'an, Shaanxi, in which children are mainly infected. However, RSV, ADV and PIV are common in Shenzhen, ${ }^{16}$ RSV and rhinovirus infection are the main pathogens in north China. ${ }^{17}$ The dynamic changes in influenza viruses can explain this result. pdm01 of H1N1 influenza virus occupied a dominant position in 2010 due to the low antibody level and high susceptibility to infectious disease in population. ${ }^{24}$ Influenza surveillance data also confirmed that influenza A H1N1 was the main strain in Shaanxi Province in 2012. ${ }^{25}$ After 2011, due to the limited immune cross-responsiveness between influenza subtypes, Flu B became the dominant strain in the infected population after 2012. ${ }^{24,25}$ 
By analyzing the detection of pathogens in different genders, we found that the positive rate of male (36.33\%) was slightly higher than that of female (35.48\%), but there was no significant difference between them, which was similar to the results of Shandong province, ${ }^{18}$ however, compared with male, women were more likely to have mixed infection, which may be attribute to pregnancy-related or hormone-related immune-suppression. Immune responses can be suppressed during the menstrual cycle and pregnancy. 26,27

The analysis of pathogens detected in different age groups showed that the positive rate of minor population was significantly higher than that of middle age and elderly, especially virus (Flu A, flu B, PIV, RSV) and mixed infection. The infection rate of Flu B was the highest, followed by MP and RSV in minors (<18years), which was similar to the previous research results in Turkey, eastern China and north China. ${ }^{12}$, 14,18 It may be associated with immature immune system in children and adolescents. What's more, malnutrition, exposure to crowded conditions, indoor air pollution, lack of breastfeeding and low birth weight can increase the risk of ARIs in children. ${ }^{28}$ Our findings confirm that IFVs and RSV are an important health threat for minors in Xi'an, which highlight the need to develop effective vaccines and new methods of treatment to improve treat virus infection in Xi'an. ${ }^{29}$

The difference of seasonal pathogens in ARIs may be related to a region's climate and demographic factors. Our study finds that eight respiratory tract pathogens can be detected throughout the year, most of which have significant high circulation in autumn and winter. The detection rate is lowest in the spring

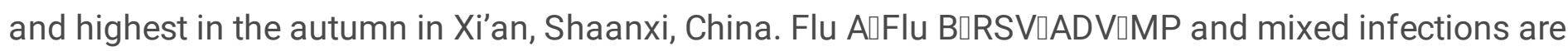
more common in autumn, LP infections are mainly in summer and autumn, this is different from previous studies in Shandong province and south China, which showed that highest detection rates were in the spring or winter. ${ }^{18,30}$

Compared with previous studies, this study has the following advantages. First, larger sample size is included in our study (15,543 samples). Second, epidemiological analysis of eight respiratory pathogens (Flu A, Flu B, PIV, RSV,ADV,MP, CP, LP) was conducted in Xi'an for the first time. Third, The etiology and epidemiology of ARIs in hospitalized children and adults were simultaneously analyzed. Four, the epidemiological characteristics of eight common respiratory pathogens in different gender, age, season and infection site are systematically analyzed, and the characteristics of pathogens under different classification conditions are summarized in detail. At the same time邓this research also has certain limitations. First, sample selection is limited to the First Affiliated Hospital of Xi'an Jiaotong University, more samples from other hospitals in Xi'an were not included systematically and comprehensively, which may result in some bias. Second, epidemiological characteristics of other pathogens such as bacteria and fungi were not analyzed. Third, the detection technology adopts the traditional IFA method instead of multiple real-time fluorescence quantitative PCR.

\section{Conclusion}


The respiratory infections reveal significant regional and seasonal differences. Flu B and MP are the most common pathogens in ARIs in Xi'an. Juveniles are more likely to be infected with the virus, and MP infection is common in adults. Juveniles are the key protected objects due to high infection rate. In summary, the results of current study provide important information for the etiology of ARIs in Shaanxi province, China, which may contribute to a reference for the health department to formulate further prevention and control plan of respiratory infection, and provide guidance for further research.

\section{Abbreviations}

ADV, Adenovirus; ARIs, Acute respiratory infection; CAP, Community acquired pneumonia; $C P$, Chlamydia pneumoniae; Flu A, Influenza virus A; Flu B, Influenza virus B; IFA, Immunofluorescence assay; LP, Legionella pneumophila; LRTIs, Lower respiratory tract infection; MCT-PCR, Multiple real-time fluorescence quantitative; MP, Mycoplasma pneumoniae; PIV, Parainfluenza virus; RSV, Respiratory syncytial virus; URTIs, Upper respiratory tract infection.

\section{Disclosures}

\section{Ethics approval and consent to participate}

This study was approved by the Ethics Review Committee of the First Affiliated Hospital of Xi 'an Jiaotong University, informed consent was waived for non-traumatic retrospective study.

\section{Consent to publication}

Written informed consent for publication was obtained from all participants.

\section{Availability of data and material}

The datasets generated and/or analyzed during the current study are not publicly available due other related research is ongoing, but are available from the author on reasonable request.

\section{Competing interests}

The authors declared no conflicts of interest in this work.

\section{Funding}

Financial support was provided by National Science and Technology Major Project (2017ZX10103004).

\section{Authors' contributions}

LM $\triangle L X Y$ and CMW conceived and designed the experiments, collectted data冈analyzed the data, contributed the materials, and wrote the manuscript. YT, HRQ and GX contributed the materials, and wrote the manuscript. All authors read and approved the final manuscript. 
Acknowledgments

Not applicable.

\section{Reference}

1. Global, regional, and national incidence, prevalence, and years lived with disability for 354 diseases and injuries for 195 countries and territories, 1990-2017: a systematic analysis for the Global Burden of Disease Study 2017. Lancet. 2018; 392: 1789-1858.

2. Estimates of the global, regional, and national morbidity, mortality, and aetiologies of lower respiratory infections in 195 countries, 1990-2016: a systematic analysis for the Global Burden of Disease Study 2016. Lancet Infect Dis. 2018; 18: 1191-1210.

3. Bicer S, Giray T, Col D, et al. Virological and clinical characterizations of respiratory infections in hospitalized children. Ital J Pediatr. 2013; 39: 22.

4. Williams B G, Gouws E, Boschi-Pinto $C$, et al. Estimates of world-wide distribution of child deaths from acute respiratory infections. Lancet Infect Dis. 2002; 2: 25-32.

5. Pavia A T. Viral infections of the lower respiratory tract: old viruses, new viruses, and the role of diagnosis. Clin Infect Dis. 2011; 52 Suppl 4: S284-289.

6. Shi T, McAllister D A, O'Brien K L, et al. Global, regional, and national disease burden estimates of acute lower respiratory infections due to respiratory syncytial virus in young children in 2015: a systematic review and modelling study. Lancet. 2017; 390: 946-958.

7. Kini S, Kalal B S, Chandy S, et al. Prevalence of respiratory syncytial virus infection among children hospitalized with acute lower respiratory tract infections in Southern India. World J Clin Pediatr. 2019; 8: 33-42.

8. Mortality, morbidity, and hospitalisations due to influenza lower respiratory tract infections, 2017: an analysis for the Global Burden of Disease Study 2017. Lancet Respir Med. 2019; 7: 69-89.

9. Guo D X, Hu W J, Wei R, et al. Epidemiology and mechanism of drug resistance of Mycoplasma pneumoniae in Beijing, China: A multi-center study. Bosn J Basic Med Sci. 2019:

10. Cui J, Yan W, Xie H, et al. A retrospective seroepidemiologic survey of Chlamydia pneumoniae infection in patients in Beijing between 2008 and 2017. PLoS One. 2018; 13: e0206995.

11. Qin T, Zhou H, Ren H, et al. Combined use of real-time PCR and nested sequence-based typing in survey of human Legionella infection. Epidemiol Infect. 2016; 144: 2006-2010.

12. Cicek $\mathrm{C}$, Arslan A, Karakus H S, et al. [Prevalence and seasonal distribution of respiratory viruses in patients with acute respiratory tract infections, 2002-2014]. Mikrobiyol Bul. 2015; 49: 188-200.

13. Yao $L H$, Wang $C$, Wei $T L$, et al. Human adenovirus among hospitalized children with respiratory tract infections in Beijing, China, 2017-2018. Virol J. 2019; 16: 78.

14. Li X, Li J, Meng L, et al. Viral etiologies and epidemiology of patients with acute respiratory infections based on sentinel hospitals in Gansu Province, Northwest China, 2011-2015. J Med Virol. 2018; 90 : 
828-835.

15. Zhang W Q, Yu J, Chen L L, et al. [Hospitalization rates for influenza-associated severe acute respiratory illness in children younger than five years old in Suzhou of China, 2016-2018]. Zhonghua Yu Fang Yi Xue Za Zhi. 2019; 53: 1056-1059.

16. Wang $\mathrm{H}$, Zheng $\mathrm{Y}$, Deng J, et al. Prevalence of respiratory viruses among children hospitalized from respiratory infections in Shenzhen, China. Virol J. 2016; 13: 39.

17. Yu J, Xie Z, Zhang T, et al. Comparison of the prevalence of respiratory viruses in patients with acute respiratory infections at different hospital settings in North China, 2012-2015. BMC Infect Dis. 2018; 18: 72 .

18. Liu T, Li Z, Zhang S, et al. Viral Etiology of acute respiratory tract infections in hospitalized children and adults in Shandong Province, China. Virol J. 2015; 12: 168.

19. Rudan I, Chan K Y, Zhang J S, et al. Causes of deaths in children younger than 5 years in China in 2008. Lancet. 2010; 375: 1083-1089.

20. Yu J, Zhang X, Shan W, et al. Influenza-associated Hospitalization in Children Younger Than 5 Years of Age in Suzhou, China, 2011-2016. Pediatr Infect Dis J. 2019; 38: 445-452.

21. Khuri-Bulos N, Lawrence L, Piya B, et al. Severe outcomes associated with respiratory viruses in newborns and infants: a prospective viral surveillance study in Jordan. BMJ Open. 2018; 8: e021898.

22. Ng K F, Tan K K, Sam Z H, et al. Epidemiology, clinical characteristics, laboratory findings and severity of respiratory syncytial virus acute lower respiratory infection in Malaysian children, 2008-2013. J Paediatr Child Health. 2017; 53: 399-407.

23. Kumar P, Medigeshi G R, Mishra V S, et al. Etiology of Acute Respiratory Infections in Infants: A Prospective Birth Cohort Study. Pediatr Infect Dis J. 2017; 36: 25-30.

24. Wabwire-Mangen F, Mimbe D E, Erima B, et al. Epidemiology and Surveillance of Influenza Viruses in Uganda between 2008 and 2014. PLoS One. 2016; 11: e0164861.

25. M Ping, JJ Wang, Y Zhang, et al.Eepidemiological characteristics and influence factors of influenza outbreak in Shaanxi province,2006-2013. Chin J Public Health. 2015; 31: 17-21.

26. Giefing-Kröll C, Berger P, Lepperdinger G, et al. How sex and age affect immune responses, susceptibility to infections, and response to vaccination. Aging Cell. 2015; 14: 309-321.

27. Klein S L, Hodgson A, Robinson D P. Mechanisms of sex disparities in influenza pathogenesis. J Leukoc Biol. 2012; 92: 67-73.

28. Walker C L F, Rudan I, Liu L, et al. Global burden of childhood pneumonia and diarrhoea. Lancet. 2013; 381: 1405-1416.

29. Mazur N I, Martinon-Torres F, Baraldi E, et al. Lower respiratory tract infection caused by respiratory syncytial virus: current management and new therapeutics. Lancet Respir Med. 2015; 3: 888-900.

30. Global, regional, and national age-sex specific mortality for 264 causes of death, 1980-2016: a systematic analysis for the Global Burden of Disease Study 2016. Lancet. 2017; 390: 1151-1210. 


\section{Tables}

Table 1

Demographic and clinical characteristics of enrolled patients with ARIs

\begin{tabular}{|c|c|}
\hline \multirow[t]{2}{*}{ Characteristics } & All patients(\%) \\
\hline & $(N=15543)$ \\
\hline \multicolumn{2}{|l|}{ Gender } \\
\hline Male & $9725(62.57)$ \\
\hline Female & $5818(37.43)$ \\
\hline Age, mean \pm standard deviation & $49.33 \pm 19.31$ \\
\hline \multicolumn{2}{|l|}{ Age in years } \\
\hline$<18$ & $4327(27.84)$ \\
\hline $18 \varangle 45$ & 3014 (19.39) \\
\hline $45 \rrbracket 69$ & $3767(24.24)$ \\
\hline$>69$ & $4435(28.53)$ \\
\hline \multicolumn{2}{|l|}{ Season of illness onset ${ }^{a}$} \\
\hline Spring & $3701(23.81)$ \\
\hline Summer & $3974(25.57)$ \\
\hline Autumn & $3246(20.88)$ \\
\hline Winter & $4622(29.74)$ \\
\hline \multicolumn{2}{|l|}{ Clinical diagnosis } \\
\hline URTIs ${ }^{b}$ & $5701(36.68)$ \\
\hline LRTIs ${ }^{c}$ & $9842(63.32)$ \\
\hline \multicolumn{2}{|c|}{$\begin{array}{l}\text { a. Spring = March to May; Summer = June to August; Autumn = September to November; } \text { Winter = } \\
\text { December to February }\end{array}$} \\
\hline \multicolumn{2}{|c|}{$\begin{array}{l}\text { b. URT Is = upper respiratory tract infections, classified when common cold, rhinitis, pharyngitis, } \\
\text { laryngitis or otitis media were diagnosed by attending physicians, etc. }\end{array}$} \\
\hline
\end{tabular}


Table 2

Detection rate of eight common pathogens of ARIs

\begin{tabular}{|c|c|c|}
\hline Pathogens & Positive number & Positive rate(\%) \\
\hline MP & 2816 & 18.12 \\
\hline Flu B & 1811 & 11.65 \\
\hline $\mathrm{CP}$ & 1088 & 7.00 \\
\hline RSV & 649 & 4.18 \\
\hline PIV & 440 & 2.83 \\
\hline Flu A & 263 & 1.69 \\
\hline LP & 156 & 1.00 \\
\hline ADV & 109 & 0.70 \\
\hline Mixed infection ${ }^{a}$ & 1419 & 9.13 \\
\hline Total & $5597^{a}$ & $36.01^{a}$ \\
\hline
\end{tabular}


Table 3

Detection rate of individual pathogens in different gender groups of ARIs

\begin{tabular}{|c|c|c|c|c|c|c|}
\hline \multirow[t]{2}{*}{ Pathogens } & \multicolumn{2}{|l|}{ Male $(\mathrm{N}=9725)$} & \multicolumn{2}{|l|}{ Female $(\mathrm{N}=5818)$} & \multirow{2}{*}{$\chi^{2}$} & \multirow[t]{2}{*}{$P$-value } \\
\hline & Positive number & $\begin{array}{l}\text { Positive } \\
\text { rate(\%) }\end{array}$ & Positive number & $\begin{array}{l}\text { Positive } \\
\text { rate(\%) }\end{array}$ & & \\
\hline Flu A & 185 & 1.90 & 78 & 1.34 & 6.90 & 0.009 \\
\hline Flu B & 714 & 7.34 & 1097 & 18.86 & 3.48 & 0.062 \\
\hline PIV & 228 & 2.34 & 212 & 3.64 & 22.34 & $<0.001$ \\
\hline RSV & 387 & 3.98 & 262 & 4.50 & 2.50 & 0.114 \\
\hline ADV & 82 & 0.84 & 27 & 0.46 & 7.51 & 0.006 \\
\hline MP & 2237 & 23.00 & 579 & 9.95 & 15.70 & $<0.001$ \\
\hline $\mathrm{CP}$ & 709 & 7.29 & 379 & 6.51 & 3.37 & 0.066 \\
\hline LP & 89 & 0.92 & 67 & 1.15 & 2.05 & 0.152 \\
\hline Mixed infection & 798 & 8.21 & 621 & 10.67 & 26.73 & $<0.001$ \\
\hline Total & $3533^{a}$ & $36.33^{a}$ & $2064^{\mathrm{a}}$ & $35.48^{\mathrm{a}}$ & 1.15 & 0.284 \\
\hline
\end{tabular}


Table 4

Detection rate of individual pathogens in different age groups of ARIs

\begin{tabular}{|c|c|c|c|c|c|c|}
\hline \multirow[t]{3}{*}{ Pathogens } & \multicolumn{4}{|l|}{ Age group } & \multirow{3}{*}{$x^{2}$} & \multirow{3}{*}{$\begin{array}{l}P \text { - } \\
\text { value }\end{array}$} \\
\hline & $<18(\%)$ & $18 \bowtie 45(\%)$ & $45 \llbracket 69(\%)$ & $>69(\%)$ & & \\
\hline & $(\mathrm{N}=4327)$ & $(\mathrm{N}=3014)$ & $(\mathrm{N}=3767)$ & $(\mathrm{N}=4435)$ & & \\
\hline Flu A & $94(2.17)$ & $44(1.46)$ & $53(1.41)$ & $71(1.60)$ & 9.07 & 0.028 \\
\hline Flu B & 759(17.54) & $129(4.28)$ & $429(11.39)$ & 494(11.14) & 9.72 & 0.021 \\
\hline PIV & $150(3.47)$ & $60(1.99)$ & $128(3.40)$ & $101(2.28)$ & 22.83 & $<0.001$ \\
\hline RSV & $355(8.20)$ & $61(2.02)$ & $131(3.48)$ & $101(2.28)$ & 86.8 & $<0.001$ \\
\hline ADV & $36(0.83)$ & $29(0.96)$ & $23(0.61)$ & $21(0.47)$ & 7.76 & 0.051 \\
\hline MP & $475(10.98)$ & 1018(33.76) & 726(19.27) & $597(13.46)$ & 134.45 & $<0.001$ \\
\hline $\mathrm{CP}$ & $295(6.28)$ & $227(7.53)$ & $287(7.62)$ & $279(6.29)$ & 7.17 & 0.067 \\
\hline LP & $39(0.90)$ & $41(1.36)$ & $42(1.11)$ & $34(0.77)$ & 7.29 & 0.063 \\
\hline $\begin{array}{l}\text { Mixed } \\
\text { infection }\end{array}$ & 478(11.05) & $211(7.00)$ & 258(6.85) & $472(10.64)$ & 72.5 & $<0.001$ \\
\hline Total & $1773^{\mathrm{a}}(40.98)$ & $\begin{array}{l}1169^{a} \\
(38.79)\end{array}$ & $\begin{array}{l}1109^{a} \\
(29.44)\end{array}$ & $\begin{array}{l}1546^{a} \\
(34.86)\end{array}$ & 129.49 & $<0.001$ \\
\hline
\end{tabular}


Table 5

Detection rate of individual pathogens in different season groups of ARIs

\begin{tabular}{|c|c|c|c|c|c|c|}
\hline \multirow[t]{3}{*}{ Pathogens } & \multicolumn{4}{|c|}{ Season group } & \multirow[t]{3}{*}{$x^{2}$} & \multirow{3}{*}{$\begin{array}{l}P \text { - } \\
\text { value }\end{array}$} \\
\hline & Spring(\%) & Summer(\%) & Autum(\%) & Winter(\%) & & \\
\hline & $(\mathrm{N}=3701)$ & $(\mathrm{N}=3974)$ & $(\mathrm{N}=3246)$ & $(\mathrm{N}=4622)$ & & \\
\hline Flu A & $59(1.59)$ & $62(1.56)$ & $39(1.20)$ & $103(2.23)$ & 13.32 & 0.004 \\
\hline Flu B & $386(10.43)$ & $317(7.98)$ & $349(10.75)$ & 759(16.42) & 162.21 & $<0.001$ \\
\hline PIV & $161(4.35)$ & $81(2.04)$ & $96(2.96)$ & $102(2.21)$ & 48.87 & $<0.001$ \\
\hline RSV & $77(2.08)$ & $122(3.07)$ & $204(6.28)$ & $246(5.32)$ & 104.02 & $<0.001$ \\
\hline ADV & $16(0.43)$ & $25(0.63)$ & $17(0.52)$ & $51(1.10)$ & 16.35 & 0.001 \\
\hline MP & 643(17.37) & 750(18.87) & $459(14.14)$ & $964(20.86)$ & 60.89 & $<0.001$ \\
\hline $\mathrm{CP}$ & $273(7.38)$ & $271(6.82)$ & $282(8.69)$ & $262(5.67)$ & 27.79 & $<0.001$ \\
\hline LP & $28(0.76)$ & $52(1.31)$ & $46(1.42)$ & $30(0.65)$ & 17.42 & 0.001 \\
\hline $\begin{array}{l}\text { Mixed } \\
\text { infection }\end{array}$ & $410(11.08)$ & 258(6.49) & $364(11.21)$ & 387(8.37) & 70.44 & $<0.001$ \\
\hline Total & $\begin{array}{l}1144^{\mathrm{a}} \\
(30.91)\end{array}$ & $\begin{array}{l}1439^{a} \\
(36.21)\end{array}$ & $\begin{array}{l}1287^{a} \\
(39.65)\end{array}$ & $\begin{array}{l}1727^{a} \\
(37.37)\end{array}$ & 64.17 & $<0.001$ \\
\hline
\end{tabular}

\section{Figures}

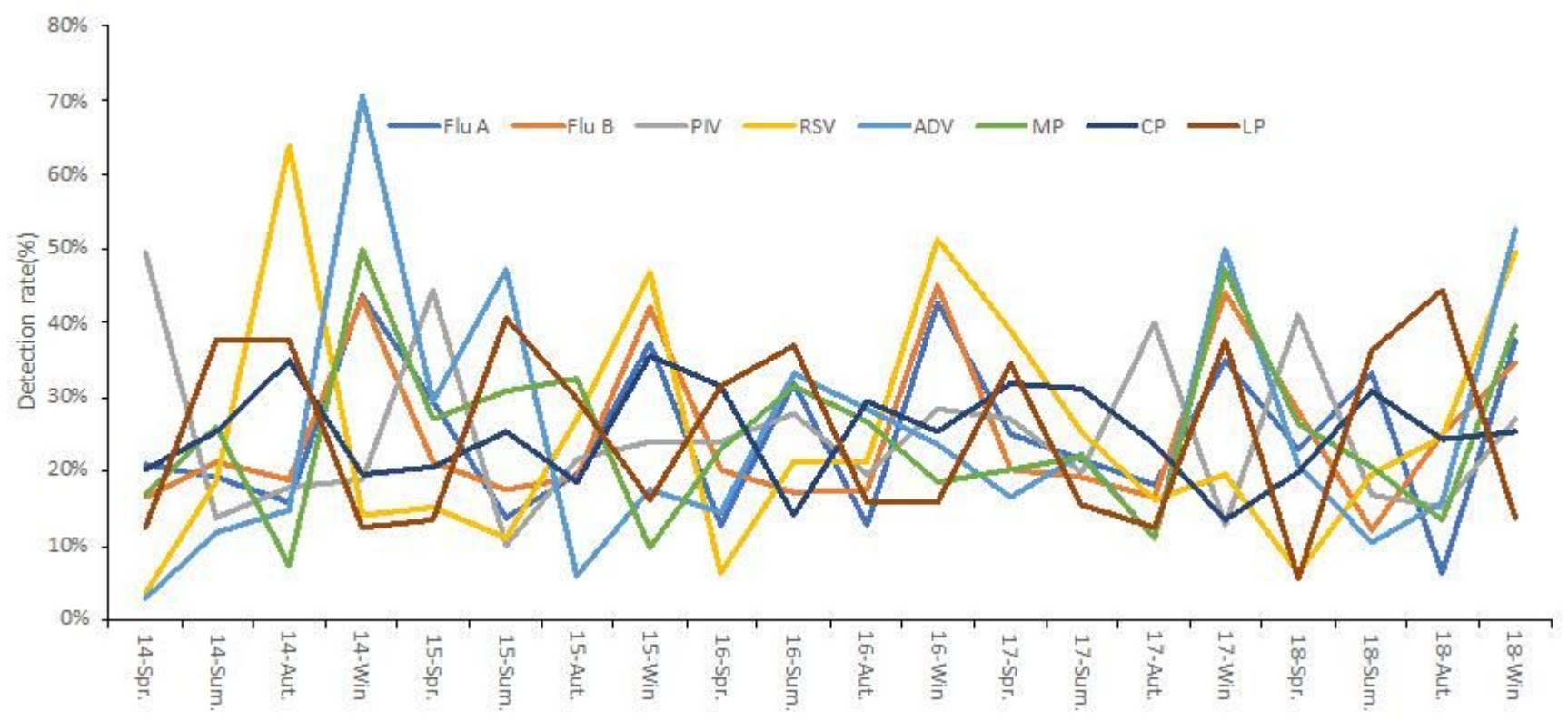


Figure 1

Seasonal detection rate of individual pathogens in ARIs 